\title{
Design and Implementation of Complex Filter for GPS Receiver
}

\author{
Feng Wei and Dai Yujie \\ College of Electronic Information and Optical Engineering, Nankai University, \\ Tianjin 300071, China \\ fengwei720720@163.com
}

\begin{abstract}
The paper proposes fourth order Butterworth complex filter for the Global Positioning System (GPS) receiver, which the center frequency of complex filter is $2 \mathrm{MHz}$ and bandwidth is $2 \mathrm{MHz}$. The operational amplifier (OPA) is designed as twostage fully differential OPA. The gain bandwidth $(G B W)$ of operation amplifier reaches $300 \mathrm{MHz}$, the gain of the $D C$ is $58.3 \mathrm{~dB}$, the phase margin is $57^{\circ}$ and the power of dissipation of operational amplifier is smaller than $0.56 \mathrm{~mW}$. The complex filter is implemented in BCD 0.18 um CMOS process. Simulation shows that the pass-band is between $1 \mathrm{MHz}$ and $3 \mathrm{MHz}$, pass-band gain is $0.592 \mathrm{~dB}$, the image rejection ratio of the complex filter is more than $-48 d B$ and power consumption is about $4.485 \mathrm{~mW}$. The parameters of the complex filter are suitable for GPS receiver.
\end{abstract}

Keywords: GPS receiver, the fourth order Butterworth complex filter, operational amplifier, center frequency

\section{Introduction}

With the rapid development of communication technology, a large number of communication systems are studied and improved such as GPS, Bluetooth, wireless network sensor and so on [1]. Modern wireless receivers and transceivers greatly desire low power consumption, which is crucial for the longer batter life [2]. In order to reduce the power consumption and the cost of chip, the integrated filter is necessary for the modern wireless receivers and transceivers [3].

Communication systems with high data rates require receivers to have a wide band channel select filter. The filter must have high dynamic range to be able to reject strong interference when receiving weak signals. Architecture of choice for such high performance filter for the receiver is active-RC complex filter [4].

This paper shows a synthesis of fourth order Butterworth complex filter which is designed by shifting low pass filter (LPF) midpoint frequency to the complex filter center frequency. Operational amplifier is an importance active device in complex filter. Because operational amplifier needs a large unity gain bandwidth than the complex filter cut-off frequency, thus, operational amplifier consumes large amounts of power. Therefore, low power consumption, wide gain bandwidth of operational amplifier is designed. The complex filter is implemented in BCD 0.18um CMOS process, and simulation results show the complex filter has a good performance.

\section{Structure of GPS Signal and Suppressing of Image Noise}

The structure of the GPS signal is shown in Figure 1(a), the most of GPS C/A signal energy is in the middle of the bandwidth of the $2 \mathrm{MHz}$. In the GPS receiver, there are a lot of noises in the receiver circuits, such as thermal noise of resistor, MOSFETS noise and bipolar transistor noise. Thus, the performance of receiver is weakened by the noise. If there is no noise or noise is suppressed to a small range, the receiver would be able to 
detect arbitrarily small signal and have a far distance communication. In order to suppress the image noise, the image reject filter is necessary as shown in Figure 1(b) [57].

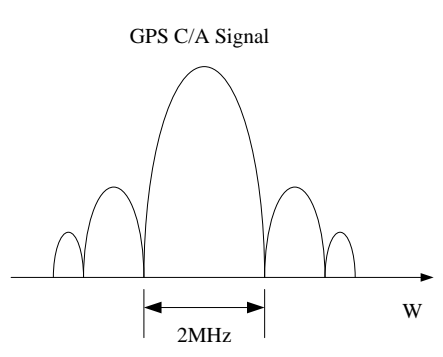

(a)

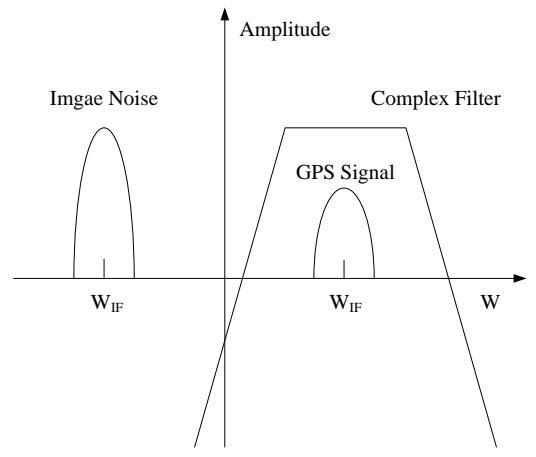

(b)

Figure 1. The Signal of GPS and Suppressing Image Noise

As the shown in Figure 2, the image noise is leaded by the quadrature downconversion. Therefore, complex filter is designed as image reject filter, which exhibits a relatively small loss in the signal and a large attenuation in the image noise.

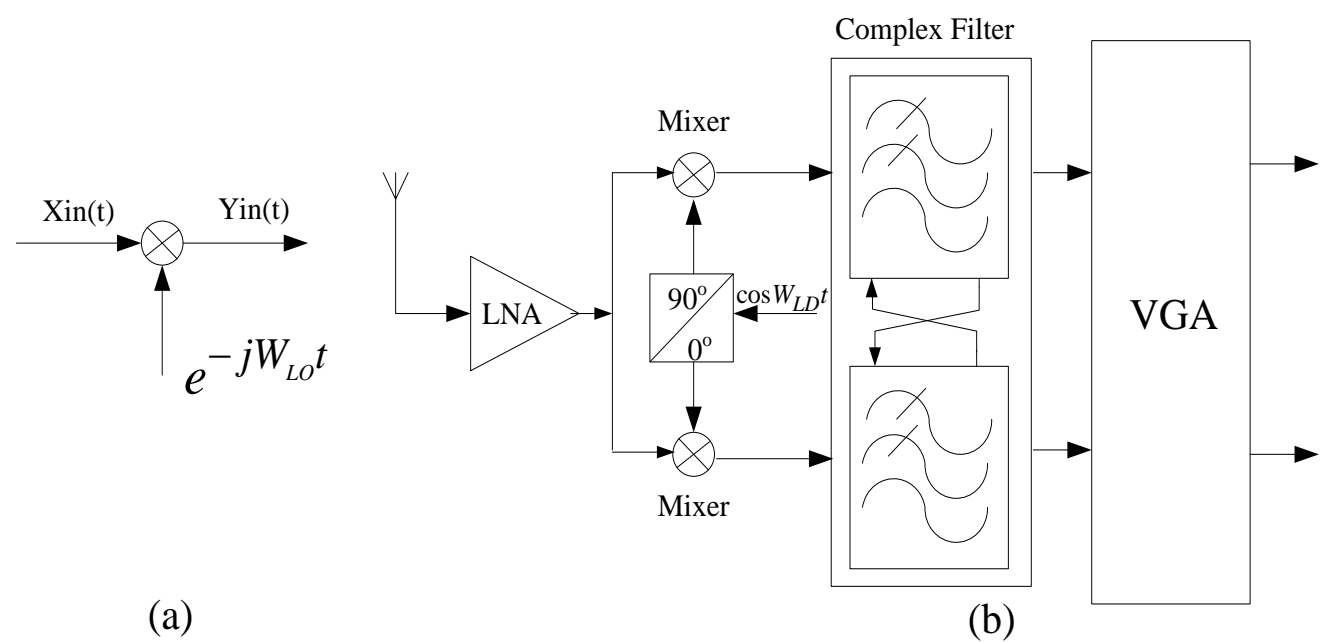

Figure 2. Diagram of Complex Filter

\section{Modeling of the Complex Filter}

In order to achieve the functions of suppressing image noise and translating useful signal, the complex can be designed by shifting LPF midpoint frequency from 0 to $W_{I F}$ as shown in Figure 3(a). In the Figure 3(b) shows that the zero-pole diagram of curve shift, which is fourth order LPF to fourth order complex filter. The relationship between LPF transfer function and complex filter transfer function is expressed as following equation:

$$
H_{\text {complex }_{-} \text {filter }}(j W)=H_{L P F}\left(j W-j W_{I F}\right)
$$

Where, the $W_{I F}$ is the center frequency of complex filter. 

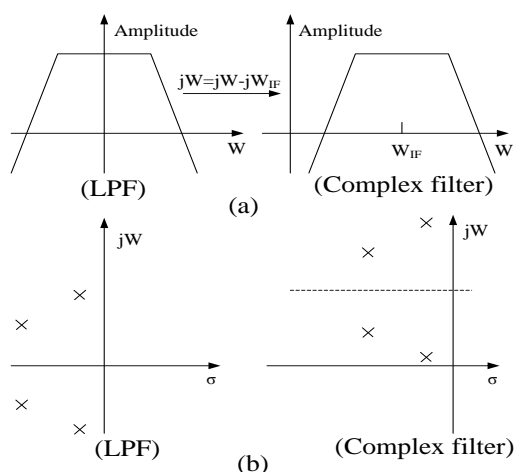

\section{Figure 3. The Converter of LPF to Complex Filter}

The first order low pass active filter is shown in Figure 4(a), where, OPA is the active device, in order to make the active device does not affect the performance of the complex filter, the GBW of OPA should be large enough. Figure 4(b) shows the equivalent diagram of the first order low pass active filter.

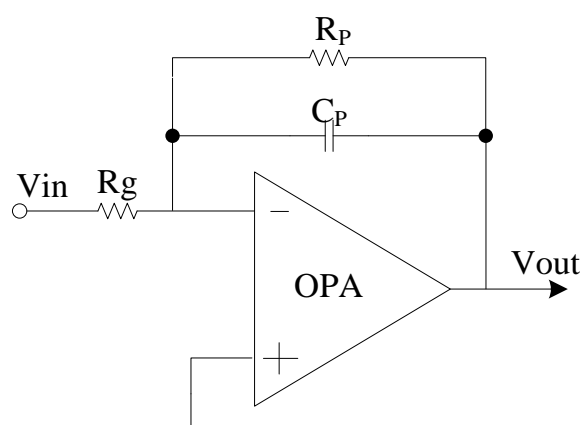

(a)

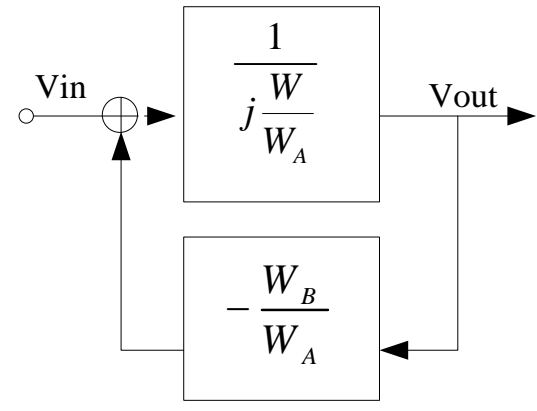

(b)

Figure 4. Schematic Circuit and Equivalent Diagram of First Order Low Pass Filter

The transfer function of the active low pass filter as shown in Figure 4(a) can be expressed as following equation:

$$
\frac{\operatorname{Vout}(S)}{\operatorname{Vin}(S)}=-\frac{\frac{1}{R_{g} C_{P}}}{\left(S+\frac{1}{R_{P} C_{P}}\right)}=-\frac{W_{A}}{S+W_{B}}
$$

Therefore, the structure of complex filter can be obtained from the structure of first order low pass active filter as shown in Figure 5(a). The equivalent diagram of the complex filter is shown in Figure 5(b). 


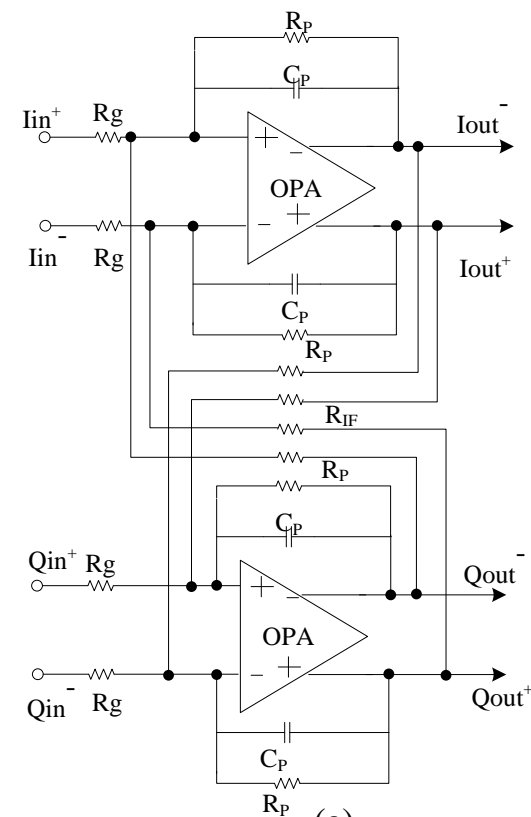

(a)

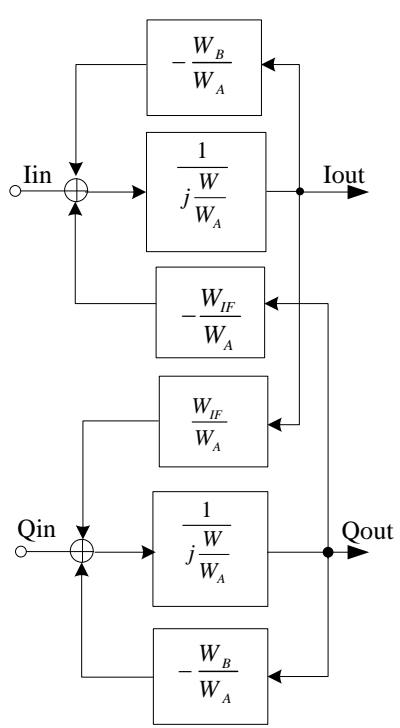

(b)

Figure 5. Schematic Circuit and Equivalent Diagram of the Complex Filter

As the shown in Figure 5, the transfer functions of the complex filter can be obtained from the equivalent diagram of the complex filter as:

$$
\begin{aligned}
& I_{\text {out }}=\left(I_{\text {in }}-\frac{W_{I F}}{W_{A}} Q_{\text {out }}-\frac{W_{B}}{W_{A}} I_{\text {out }}\right) \frac{1}{j W / W_{A}} \\
& Q_{\text {out }}=\left(Q_{\text {in }}+\frac{W_{I F}}{W_{A}} I_{\text {out }}-\frac{W_{B}}{W_{A}} Q_{\text {out }}\right) \frac{1}{j W / W_{A}}
\end{aligned}
$$

From equations (3) and (4), the transfer function of the complex filter $H_{C F}(j w)$ can be calculated as:

$$
H_{C F}(j w)=\frac{I_{\text {out }}+j Q_{\text {out }}}{I_{\text {in }}+j Q_{\text {in }}}=\frac{W_{A}}{j W-j W_{I F}+W_{B}}
$$

Where,

$$
W_{A}=\frac{1}{R_{g} C_{P}}, W_{B}=\frac{1}{R_{P} C_{P}}, W_{I F}=\frac{1}{R_{I F} C_{P}} .
$$

Comparing equations (1) and (5), it would be prove that the complex filter can be achieved as image reject filter, which can be shifted to a certain frequency from the LPF with the same bandwidth.

\section{The Design of Operational Amplifier}

The operational amplifier is two-stage fully differential OPA with miller compensation capacitance and common mode feedback as shown in Figure 6. In such structure, the first stage provides high gain, the second stage offers a large voltage swing. 


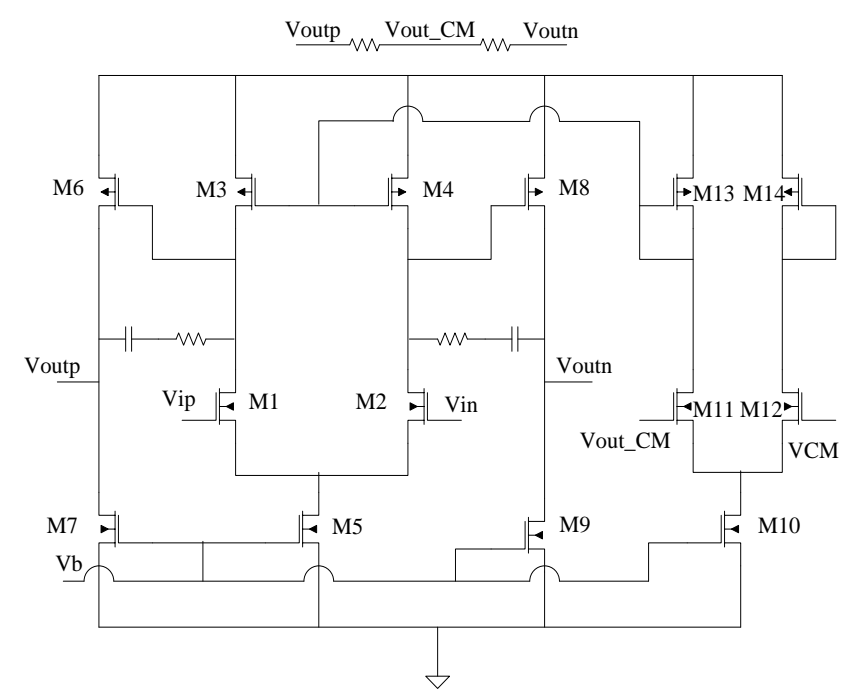

Figure 6. Schematic of Operational Amplifier

The GBW of operational amplifier should be wide enough to make the actual operational amplifier minimize the impact on the performance of the complex filter. The GBW of the operational amplifier should satisfy as [8]:

$$
G B W \geq\left|\frac{A_{c}\left(j W_{L}\right)}{\delta}-1\right| \cdot\left|\left[1+A_{c}\left(j W_{L}\right)\right] \bullet W_{L}\right|
$$

Where, the $A_{c}\left(j W_{L}\right)$ is the close-loop gain of the operational amplifier, the $W_{L}$ is the bandwidth of filter, $\delta$ is the error between ideal transform function and non-ideal transform function. From the equation (6), if the cut-off frequency of complex filter is $\omega$, the GBW of operational amplifier should be about $100 \omega$.

Because the centre frequency of the complex filer is $2 \mathrm{MHz}$ and the bandwidth is $2 \mathrm{MHz}$, thus, the cut-off frequency of the complex filter is $3 \mathrm{MHz}$, therefore, the GWB of operational amplifier should be about $300 \mathrm{MHz}$. As the shown in Figure 7, simulation shows that the GWB of the operational amplifier is $300 \mathrm{MHz}$, the gain of $\mathrm{DC}$ is $58.3 \mathrm{~dB}$, the phase margin is $57^{\circ}$, and the power dissipation is $0.56 \mathrm{~mW}$. Through simulation in all corners, these parameters are satisfied.

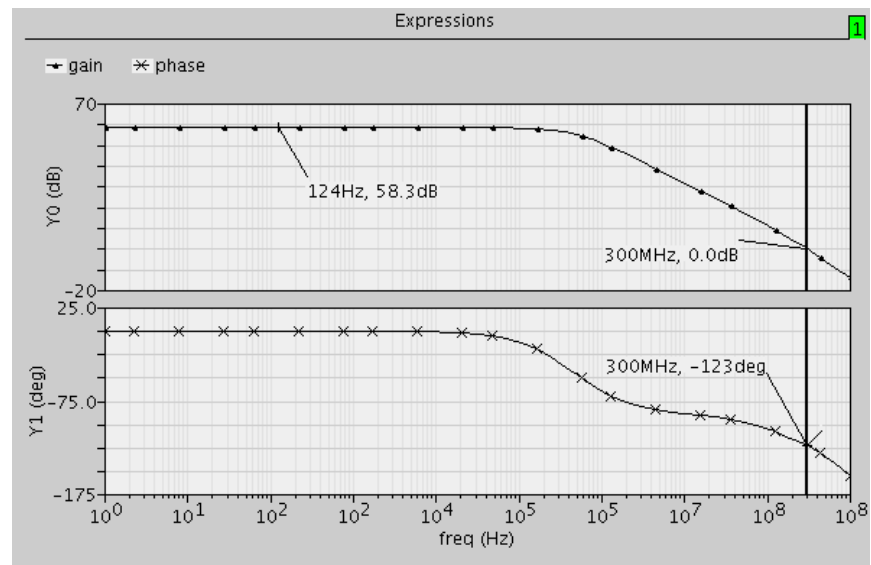

Figure 7. Simulation of Operational Amplifier 


\section{Implementation of the Complex Filter}

In order to achieve a stronger suppression on image noise, sharp transition-band frequency response and have a flat pass-band, the fourth order Butterworth filter is chosen as shown in Figure 8.

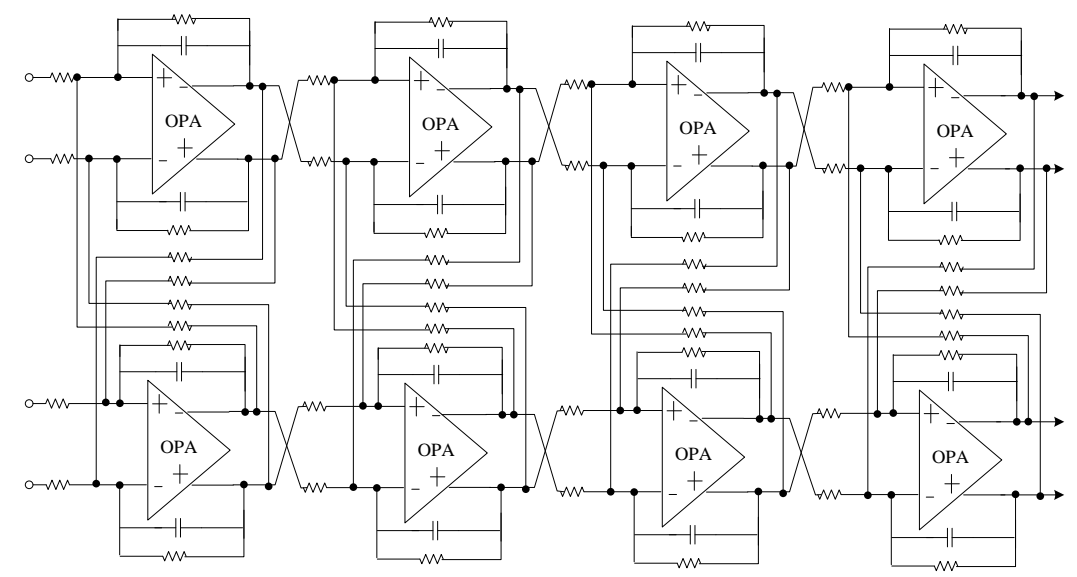

Figure 8. Schematic Circuit of the Fourth Order Complex Filter

As the variations of manufacturing process and environment temperature, the values of capacitors and resistances significant change, these make RC time constant of the complex filter change. Therefore, the center frequency and bandwidth of the complex filter are drifted. In order to conquer the problem, a tuning system is necessary.

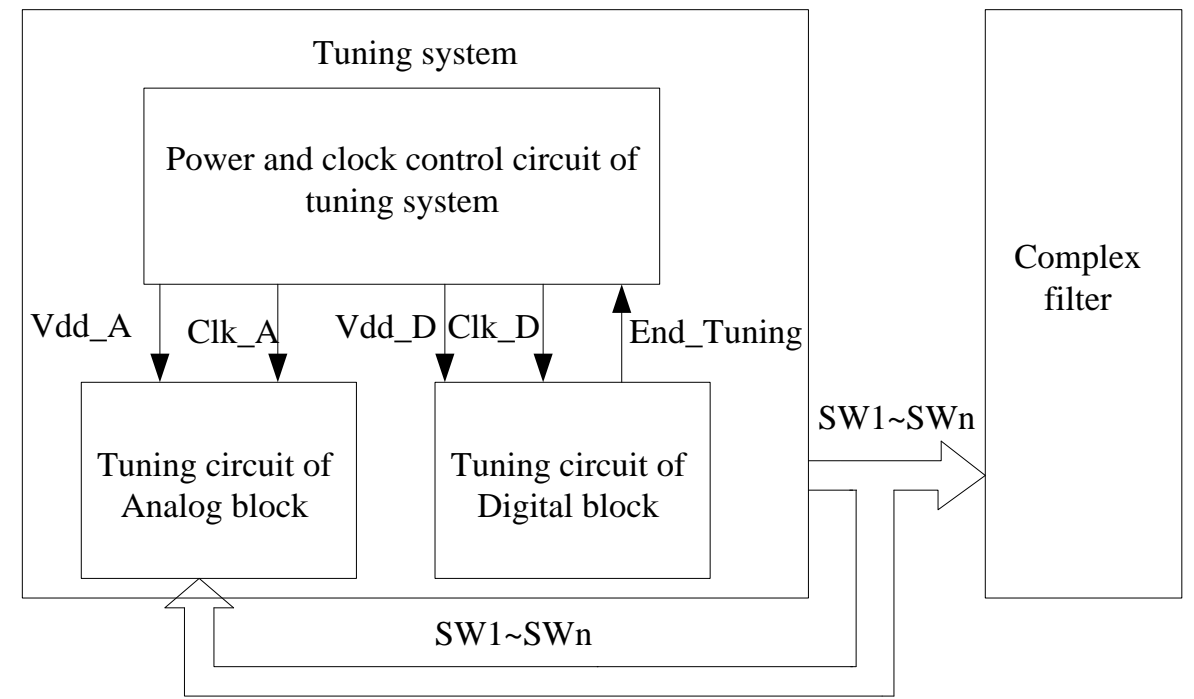

Figure 9. Diagram of the Tuning System

Figure 9 shows the diagram of the tuning system. The tuning circuits are realized by adjusting the values of capacitors of the complex filter. The implementation circuits of the tuning system are shown in [9].

\section{Simulation and Analysis}

The complex filter is implemented in BCD 0.18 um CMOS process. The input signals are sent into the complex filter. The input signals of complex filter are the 
quadrature sinusoidal signals, which are in four different phases, the phases of signals are $0^{\circ}, 180^{\circ}, 90^{\circ}$ and $270^{\circ}$.

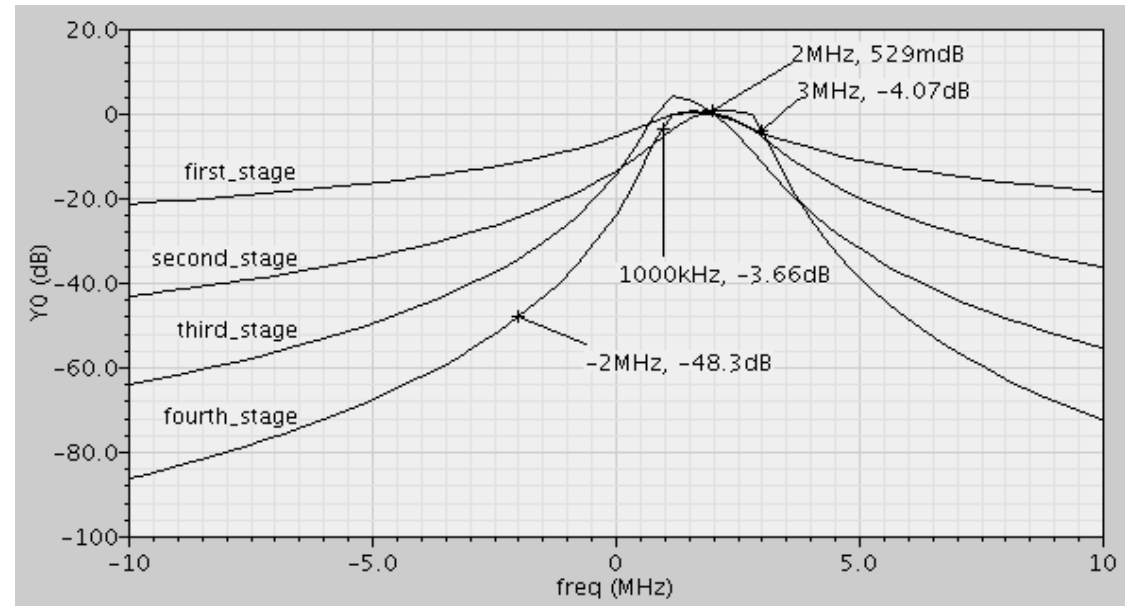

(a)

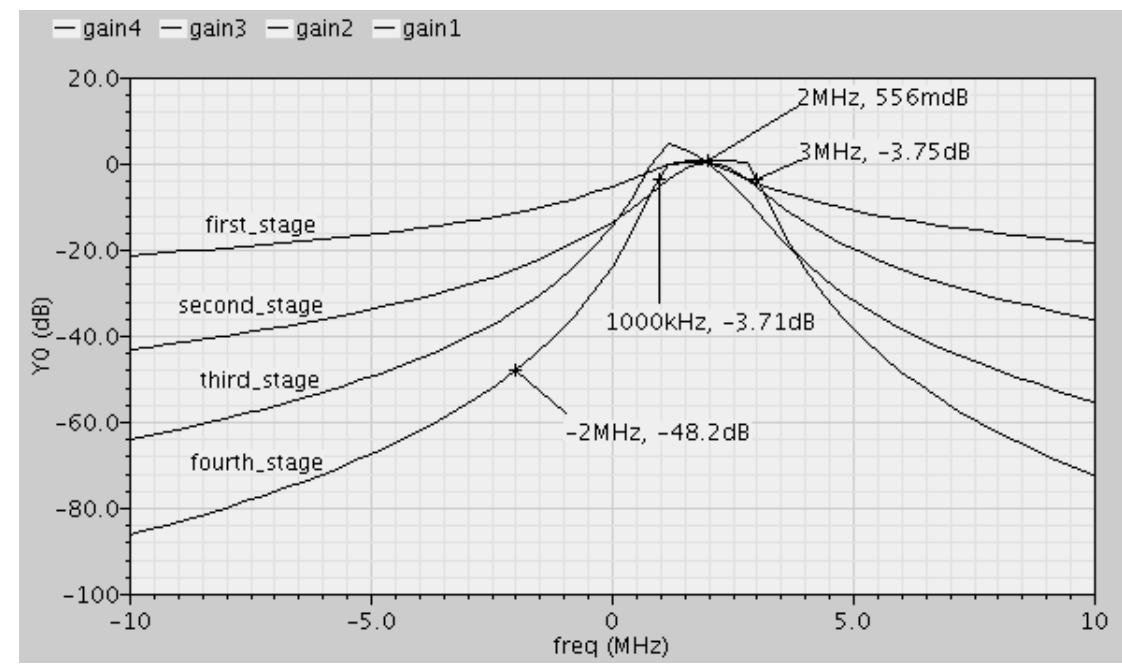

(b)

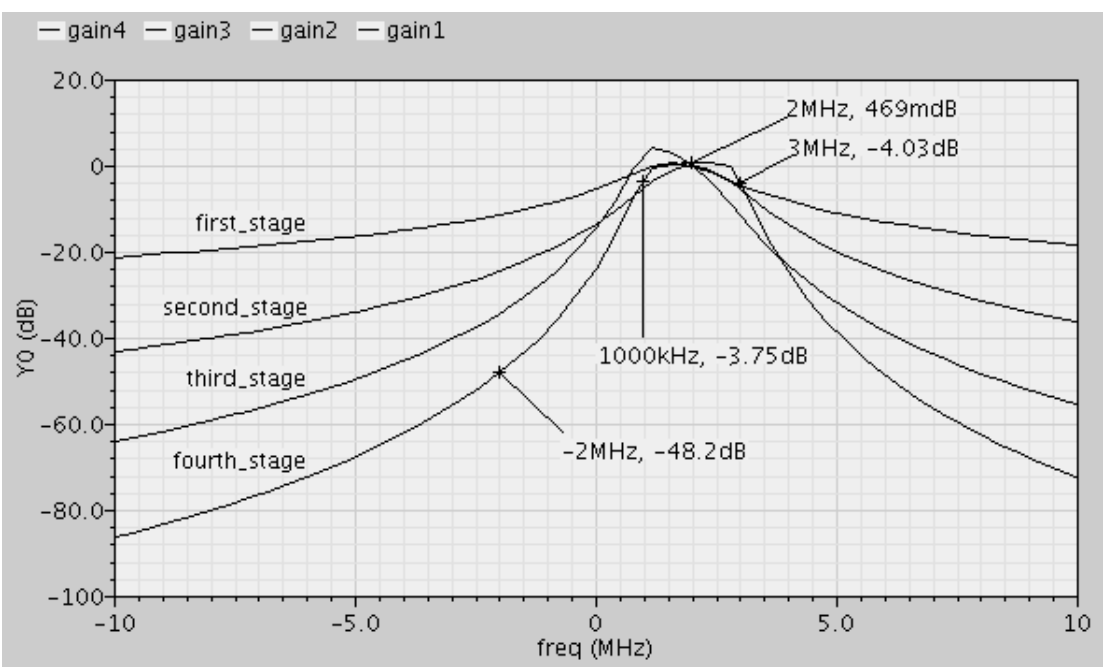

(c)

Figure 10. Simulation of the Complex Filter 
The simulations for AC frequency response after tuning frequency are shown in Figure 10. The Figure 10(a) shows the waveform, when the process corner is tt, the temperature is $25^{\circ}$. The Figure 10(a) shows that the center frequency is $2 \mathrm{MHz}$, and the pass-band is between $1 \mathrm{MHz}$ and $3 \mathrm{MHz}$, the pass-band gain is about $0.592 \mathrm{~dB}$. The image rejection ratio of the complex filter is more than $-48 \mathrm{~dB}$ and the power consumption of the complex filter is about $4.485 \mathrm{~mW}$.

The Figure 10(b) shows the waveform is that the process corner is ss, the temperature is $-20^{\circ}$. The simulation conditions of the Figure 10(c) are that the process corner is $\mathrm{ff}$, and the temperature is $85^{\circ}$. The simulation results of different process corners are shown in Table 1.

Table 1. Simulation Results of the Complex Filter

\begin{tabular}{c|l|l|l}
\hline & $\mathrm{tt}$ & $\mathrm{ss}$ & $\mathrm{ff}$ \\
\hline $2 \mathrm{MHz}$ & $0.529 \mathrm{~dB}$ & $0.556 \mathrm{~dB}$ & $0.469 \mathrm{~dB}$ \\
\hline $1 \mathrm{MHz}$ & $-3.66 \mathrm{~dB}$ & $-3.71 \mathrm{~dB}$ & $-3.75 \mathrm{~dB}$ \\
\hline $3 \mathrm{MHz}$ & $-4.07 \mathrm{~dB}$ & $-3.75 \mathrm{~dB}$ & $-4.03 \mathrm{~dB}$ \\
\hline $\begin{array}{c}\text { Image } \\
\text { Rejection }\end{array}$ & $-48.3 \mathrm{~dB}$ & $-48.2 \mathrm{~dB}$ & $-48.2 \mathrm{~dB}$ \\
\hline $\begin{array}{c}\text { Power } \\
\text { Consumption }\end{array}$ & $4.485 \mathrm{~mW}$ & $4.118 \mathrm{~mW}$ & $5.043 \mathrm{~mW}$ \\
\hline
\end{tabular}

The performance of summary of the complex filter is shown in Table 2

Table 2. Performance Summary of the Complex Filter

\begin{tabular}{|l|l}
\hline Technology & BCD $0.18 \mathrm{um}$ \\
\hline Supply Voltage & $1.8 \mathrm{~V}$ \\
\hline Power consumption & $4.485 \mathrm{~mW}$ \\
\hline Center Frequency & $2 \mathrm{MHz}$ \\
\hline Bandwidth & $2 \mathrm{MHz}$ \\
\hline Pass-band Gain & $0.529 \mathrm{~dB}$ \\
\hline Image Rejection Ration & $-48.3 \mathrm{~dB}$ \\
\hline
\end{tabular}

\section{Conclusion}

This paper has presented a complex filter for GPS receiver, which is based on fourth order Butterworth low pass filter, and is implemented in BCD 0.18um CMOS process. The two-stage fully differential operational amplifier is designed for the complex filter, the GBW of the operational amplifier is about $300 \mathrm{MHz}$ and the power dissipation is about $0.56 \mathrm{~mW}$. The simulation results of the complex filter show that the center frequency of the complex filter is $2 \mathrm{MHz}$, the image rejection ration is $-48.3 \mathrm{~dB}$, and the power consumption of the complex filter is smaller than $4.49 \mathrm{~mW}$. 


\section{Acknowledgements}

This work was supported by the Tianjin Science and Technology Project (13ZCZDGX04100).

\section{References}

[1] W. Wang, G. He and J. Wan, "Research on Zigbee wireless communication technology", Proceedings of the IEEE International Conference on Electrical and Control Engineering (ICECE), Yichang, (2011), pp. 1245-1249.

[2] L. Ye, C. Shi, L. Huailin, R. Huang and Y. Wang, "Highly Power-Efficient Active Filters with Wide Bandwidth Range Using Low-Gain Push-Pull Opamps", Circuits and Systems I: Regular Papers, IEEE Transactions, vol. 60, no. 1, (2013), pp. 95-107.

[3] K. Yazawa and H. Tanimoto, "Design and implementation of 0.8-V Active RC poly-phase filter using 0.18 um CMOS inverters with resistive level shift", Proceedings of the IEEE International Symposium on Circuits and System (ISCAS), Taipei, (2009), pp. 2958-2961.

[4] M. Abdulaziz, A. Nejdel, tormannen.M, Sjoland.H. A $3.4 \mathrm{~mW} 65 \mathrm{~nm}$ CMOS $5^{\text {th }}$ order programmable active-RC channel select filter for LTE recevers. Proceedings of the IEEE International Conference on Radio Frequency Integrated Circuits Symposium (REIC), June, Seattle, WA, (2013), pp. 217-220.

[5] M.S. Braaasch and A.J. Van Dierendonck, "GPS receiver architectures and measurements", Proceeding of the IEEE, vol. 87, no. 1, (1999), pp. 48-64.

[6] E. Wang, S. Zhang, Q. Hu, J. Yi and X. Sun, "Implementation of an Embedded GPS Based on FPGA and MicroBlaze", Proceedings of the IEEE International Conference Wireless Communication, Dalian, (2008), pp. 1-4.

[7] R.A. Monzingo, "Robust GPS receiver for multipath immunity", Proceedings of the IEEE International Conference on Aerospace Conference, Big Sky, MT (2010), pp. 1-4.

[8] L. Zou, K. Han, Y. Liao, H. Min and Z. Tang, "A $12^{\text {th }}$ order active-RC filter with automatic frequency tuning for DVB Tuner applications", Proceedings of the IEEE International Conference on Solid-State Conference, Fukuoka, (2008), pp. 281-284.

[9] D.K. Du, Y. Li, Z. Wang and S. Tan, "An Active-RC Complex Filter with Mixed Signal Tuning System for Low-IF Receiver", Proceedings of the IEEE International Conference on Circuits and Systems, Singapore, (2006), pp. 1031-1034.

\section{Authors}

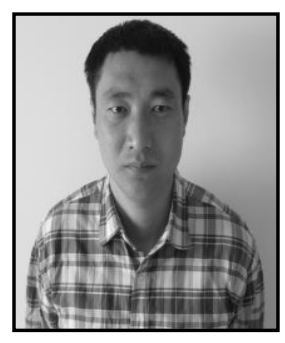

Feng Wei, received his Engineer Master degree from Henan University of Science and Technology, China, in 2005. Currently, he is working toward the Ph.D. degree in Nankai University. The main research directions: analog integrated circuit design.

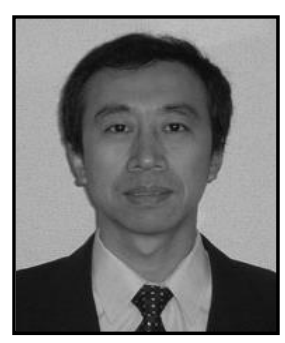

Dai Yujie, received his Engineer Master degree from Taiyuan University of Technology, China, in 1984. He received his Ph.D. from TOHOKU UNIVERSITY, Japan, in 1992. The main research directions: the SOC design of nanometer CMOS process, mixed analog-digital integrated circuit, analog integrated circuit. 
International Journal of Control and Automation Vol.8, No.12 (2015) 